\title{
A escrita de casos clínicos: dos efeitos no analista e da transmissão da psicanálise
}

\author{
The writing of clinical cases: from the effects on the analyst and the transmission of psychoanalysis \\ La escritura de casos clínicos: de los efectos sobre el analista y de la transmisión del psicoanálisis
}

Recebido: 20/08/2021 | Revisado: 28/08/2021 | Aceito: 29/08/2021 | Publicado: 01/09/2021

\author{
Arina Marques Lebrego \\ ORCID: https://orcid.org/0000-0003-3457-7513 \\ Universidade Federal do Pará, Brasil \\ E-mail: arinamlebrego@gmail.com \\ Breno Ferreira Pena \\ ORCID: https://orcid.org/0000-0003- 4485-3673 \\ Universidade Federal do Pará, Brasil \\ E-mail: brenopena@hotmail.com
}

\begin{abstract}
Resumo
O presente trabalho se propôs a investigar os possíveis efeitos da escrita de um caso clínico para o analista e para a transmissão. Para tanto, empreendemos uma pesquisa teórica em psicanálise, que teve como fruto este ensaio. Como resultados e discussões elaboramos duas seções. A primeira destaca o lugar do caso clínico como privilegiado e original no desenvolvimento de pesquisas psicanalíticas, demarcando funções a partir de sua escrita, entre elas, interrogar a teoria, problematizar o encontro analítico em sua dimensão singular e propiciar a ancoragem para construções metapsicológicas. Na segunda seção, discutimos acerca dos efeitos da escrita do caso para o psicanalista que, em seu trabalho de composição escrita, pode fazer o luto do processo vivido, como parte de uma elaboração necessária para a dissolução da lógica transferencial. Abordamos ainda como a transmissão opera em seu valor de possibilidade/incompletude, marcada pelo real da clínica. Como considerações finais, destacamos a dimensão nãotoda da escrita, acima de tudo, a aposta de que não devemos recuar frente ao desafio de escrever a clínica.
\end{abstract}

Palavras-chave: Psicanálise; Escrita de caso clínico; Transmissão; Analista.

\begin{abstract}
The present work aimed to investigate the possible effects of writing a clinical case for the analyst and for transmission. For this, we undertook a theoretical research in psychoanalysis, which resulted in this essay. As results and discussions, we elaborated two sections. The first highlights the position of the clinical case as privileged and original in the development of psychoanalytic research, demarcating functions as from its writing, among them, interrogating the theory, problematizing the analytical encounter in its singular dimension and provide the anchorage for metapsychological constructions. In the second section, we discuss about the effects of the writing of the case for the psychoanalyst who in your writing composition work, can mourn the lived process, as part of a necessary elaboration for the dissolution of transferential logic. We also discuss how the transmission operates in its value of possibility/ incompleteness, marked by the real of the clinic. As final considerations, we highlight the not-all dimension of writing, above all the bet that we should not retreat in the face of the challenge of write the clinic.
\end{abstract}

Keywords: Psychoanalysis; Clinical case writing; Transmission; Analyst.

\section{Resumen}

El presente trabajo tiene como objetivo investigar los posibles efectos de la escritura de un caso clínico para el analista y para la transmisión. Para ello, emprendimos una investigación teórica en psicoanálisis, que resultó en este ensayo. Como resultados y discusiones elaboramos dos apartados. El primero destaca el lugar del caso clínico como privilegiado y original en el desarrollo de la investigación psicoanalítica, delimitando funciones de su escritura, entre ellas, cuestionar la teoría, problematizar el encuentro analítico en su dimensión singular y proporcionar el anclaje para construcciones metapsicológicas. En el segundo apartado, se discuten los efectos de la escritura del caso para el psicoanalista que, en su trabajo de composición escrita, le posibilita elaborar el duelo del proceso vivido, como parte de una elaboración necesaria para la disolución de la lógica transferencial. También discutimos como opera la transmisión en su valor de posibilidad/incompletitud, marcado por lo real de la clínica. Como consideraciones finales, destacamos la dimensión no-toda de la escritura, sobre todo, la apuesta de que no debemos retroceder ante el desafio de escribir la clínica.

Palabras clave: Psicoanálisis; Escritura de caso clínico; Transmisión; Analista. 


\section{Introdução}

O tema e a produção do presente artigo emergiram do desejo de sustentar a importância da escrita de casos clínicos em contextos de produção de pesquisas em psicanálise, como no âmbito de uma pós-gradução stricto sensu. Neste locus, as reflexões acerca de material clínico visando publicações é algo recorrente, atravessando o cotidiano dos analistas que se ocupam de pesquisas em universidades. Nessa tradição, é de conhecimento de todos que este material não é comunicado em seu estado bruto, ou seja, ele vem mediado por formulações de hipóteses e teorias.

Inicialmente, é valido tecer breves linhas acerca do que é um caso clínico psicanalítico. Segundo Nasio (2001), a palavra "caso" é um relato de uma experiência singular escrito por um analista para atestar seu encontro com um paciente e ancorar um avanço teórico. Já o termo "clínica" refere-se a debruçar-se sobre o leito do paciente e produzir um saber a partir daí (Figueiredo, 2004).

Para Souza (2000), o caso é uma ficção clínica resultante de uma hipótese teórica. Designa o interesse muito particular de um analista sobre a direção de um tratamento analítico, o que leva, muitas vezes, a um intercâmbio de experiências com colegas, seja na forma de supervisão, seja na forma de grupos de estudo e pesquisas, entre outras formas. Sendo assim, o caso exprime a própria singularidade do ser que sofre e da fala que ele nos dirige.

É valido ressaltar que, no intuito de justificar a relevância da questão norteadora deste estudo, podemos apontar, na literatura, críticas atuais da casuística freudiana tecida por alguns autores (Rozen,1995; Crews, 1995; Borsch-Jacobsen, 2012) que argumentam, por diferentes caminhos, que não se pode confiar na fidedignidade dos relatos de casos freudianos (Elizabeth Von R., Lucy, Emmy Von N, Anna O. e Katharina, Caso Hans, Homem dos Lobos, Homem dos Ratos ou Dora). Entrevistando ou coligando material histórico relativo à forma como Freud praticava a psicanálise, eles apontaram diferenças entre o que aconteceu nas sessões e o que foi publicado, o que supostamente geraria pouca confiabilidade na teoria e na técnica psicanalítica (Dunker, Ramirez \& Assadi, 2017).

Desde as primeiras linhas é válido esclarecer que os critérios de cientificidade da psicanálise são outros. Na escrita de seus casos clínicos, Freud subverteu os pressupostos da clínica médica - a observação e o relato de sintomas -, inaugurando a construção metapsicológica, apresentando e representando a concepção de psicopatológico, que formou os alicerces dos fundamentos da psicanálise. Assim sendo, decantou a clínica e transmitiu dela o caso, que não se limita ao paciente, mas se refere ao encontro que a clínica promove (Oliveira, 2004; Vorcaro, 2018).

Nasio (2001) destaca que a escrita de um encontro clínico nunca é o reflexo fiel de um fato concreto, mas sua reconstituição fictícia. O apresentado/escrito nunca é um acontecimento puro e exato, mas uma história reformulada e construída a partir das lembranças de uma experiência terapêutica. É uma ficção, uma construção por justamente passar pelo filtro da vivência do analista e de seu arcabouço teórico.

$\mathrm{O}$ ato de escrever tem acompanhado a psicanálise desde seu nascimento, haja vista que, a partir da publicação da obra freudiana, a psicanálise trilhou avanços, recuos e retornos. Neste ensaio, nos ocupamos de tecer reflexões acerca da escrita de casos clínicos psicanalíticos, tendo em vista sua importância e seu valor de alicerce para a edificação da teoria psicanalítica.

Nesse contexto de pesquisa psicanalítica retrospectiva que é realizada com casos já encerrados, a escrita requer a montagem de sua trama. Ela não é uma escrita qualquer. Ela mostra como quem escreve o caso - o psicanalista - apreende e transmite a psicanálise. Mostra a sua relação com a linguagem e como expõe seus traços por meio da sua experiência clínica (Leitão, 2018). A autora toca em um ponto de relevância para este trabalho, a saber, a transmissão.

Segundo Rosa (2001) e Fernandes (2017), é necessário demarcar que a transmissão é diferente do ensino. O ensino é sustentado pela via dos conceitos, em que se ensina um saber sobre algo que já foi formulado e, por essa via, encontra-se cristalizado. Esse fato pode passar a ideia de plenitude, assim como a impressão de uma psicanálise capaz de explicar e resolver todas as questões. 
Por sua vez, a transmissão, no sentido empregado por Lacan ao reportar-se à formação de analistas, referenda o tripé enunciado por Freud - análise pessoal, supervisão e estudo teórico. Desta forma transmissão da psicanálise envolve um para além do ensino, "pois o estilo que se transmite enreda, por conta e obra da relação transferencial, o saber - da psicanálise e do analista como semblante de Sujeito-suposto-saber - e a verdade - do desejo do sujeito e de sua castração fundante" (Almeida, 2006 p. 1)

Aqui é válido, também, destacar que estamos interessados na transmissão daquilo que os analistas puderam escrever e produzir com base nas análises que conduziram (Quinet, 2009). Nogueira (1997) afirma que a "transmissão da experiência analítica no nível da escrita é uma substituição do vivido, uma espécie de laboratório, uma experiência artificial onde produzimos fatos científicos" (p. 140).

Destacamos ainda que o escritor que se propõe a escrever se vê capturado inicialmente pelo enigma do caso e depois pelos enigmas aos quais é lançado quando visita a teoria. A posteriori, no percurso de sua pesquisa retrospectiva, se vê defrontado com os efeitos dessa escrita e de sua função. Aqui já bordejamos a nossa questão norteadora: Quais os efeitos e função da escrita de um caso clínico em psicanálise para o analista e para a transmissão?

Nas linhas a seguir teceremos algumas articulações a fim de formular reflexões para a questão apresentada.

\section{Metodologia}

Visando alcançar o objetivo proposto, empreendemos a construção de um ensaio fruto de uma pesquisa teórica em psicanálise. A partir das contribuições de autores tais como Loureiro (2002), Tavares e Hashimoto (2013), propomos algumas etapas no fazer pesquisa teórica em psicanálise:

a) Delimitar um objeto específico de interesse para pesquisa.

b) Deste objeto, poderão emergir contribuições teórico-reflexivas. Vale destacar que, para a elaboração das seções teóricas, extraímos algumas reflexões de textos freudianos e lacanianos e seus comentadores especialistas no tema.

c) $\mathrm{Na}$ análise e na tessitura das discussões, devemos considerar que, em se tratando de uma pesquisa teórica, existe a transferência, pois quando nos propomos a empreender uma articulação teórica, qualquer que seja ela, a nossa racionalidade está ativa assim como os processos inconscientes, e isso deve ser considerado na pesquisa, o que situamos nas considerações finais deste ensaio de forma não-toda e incompleta por estarem em jogo aspectos latentes.

d) Após a análise e a articulação de conceitos atravessados pelas subjetividades dos autores, teremos, como produto, um ensaio ou um texto metapsicológico. Esse ensaio poderá ser constituído por um certo modelo de escrita e pensamento teórico-clínicos fornecidos pela psicanálise a seus pesquisadores, modelos cujas bases se encontram na obra de Freud. Embora não normatizados, parece lícito supor que a experiência de leitura dos textos freudianos acaba por imprimir certo tipo de estilo de pensamento e de escrita nos pesquisadores na frequentação desses textos.

e) A produção de um texto metapsicológico é posta à prova mediante sua relação com a alteridade representada pelos pares de um determinado campo de saber, quando da publicação do texto.

Vale ressaltar que a perspectiva metodológica escolhida pelos autores visa tecer reflexões e análises acerca do tema eleito, mas não tem a pretensão de apresentar uma solução substanciada e completa, haja vista que se ocupa em sua essência da palavra, evocando o estilo, a estética e o espirito do pensamento em ato (ABED, s/d). 


\section{Resultados e discussão}

Do lugar e das funções do caso clínico na pesquisa psicanalítica

Às vezes escrever uma só linha basta para salvar o próprio coração. Clarice Lispector

Dunker (2018) destaca que a psicanálise é um método bífido, de pesquisa e tratamento. E propõe que cada uma dessas vertentes do método psicanalítico possa ser formalizada como uma superfície de Moebius. Isso significa que nem a clínica nem a investigação psicanalítica devem ser pensadas fechadas sobre si mesmas, e seus conceitos e noções aplicam-se em regime de fechamento em cada um desses universos conceituais e discursivos. Método de tratamento e método de investigação são como a banda de Moebius, cada qual com uma torção em sentido contrário à outra, em acordo com a relação proposta por Lacan para a psicanálise em extensão e a psicanálise em intensão. Portanto, o método de investigação executa uma torção sem ruptura em relação ao método de tratamento.

A banda de Moebius (Figura 1) é um dos objetos topológicos apresentados por Lacan, que se propõe a dar conta da estrutura do sujeito. A banda de Moebius é um objeto de construção simples, ilustrado por uma tira de papel que se coloca sobre si mesma com um movimento de torção. Representante do irrepresentável, ela não tem avesso nem direito, é o tempo que faz a diferença entre as duas faces. A banda é também o símbolo do infinito, pois representa um caminho sem começo e sem fim. É possível percorrer toda a superfície da fita que aparenta ter dois lados devido ao efeito de torção quando na verdade tem um só (Monteiro, 2014).

Figura 1: Banda de Moebius.

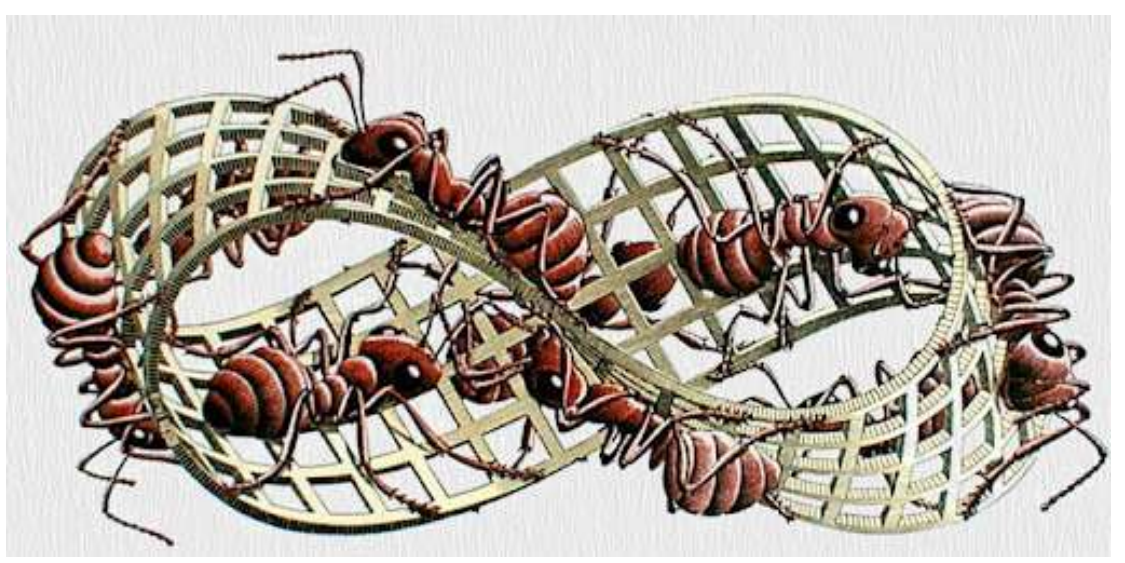

Fonte: Associação A clínica freudiana. Disponível em: http://www.clinicafreudiana.com.br/freudiana2.qps/Ref/SYSK-AVT5TS.

A pesquisa em psicanálise depende fundamentalmente da prática de seu método. Como em qualquer disciplina, é o método que sustenta a regularidade de procedimentos, a persistência de problemas e o consenso de conceitos e termos. Como citado anteriormente, Freud definiu a psicanálise como um método de tratamento e de investigação. Na prática clínica, os fins atinentes a cada um desses métodos estão em conjunção ou se recobrem. Freud é generoso na exposição do método de tratamento, descrevendo-o ao longo de sua obra diversas vezes (importância da etiologia sexual, introdução de conceitos como transferência, interpretação e resistência). No entanto, pouco escreveu acerca do método de investigação (Dunker, 2018).

Considerando o exposto quando dizemos que a psicanálise é um método, deveríamos nos ater mais ao fato de que ela congrega uma multiplicidade de estratégias, e incluir entre as formas do método clínico, os métodos hermenêuticos estruturais e as diversas modalidades de discurso. Contudo, não se pode negar que a fonte primeira e original de seu método seja a 
experiência direta com o paciente ao longo de tratamentos, cuja expressão é chamada caso clínico.

Conforme Dunker, Ramirez e Assadi (2017), se Freud definia a psicanálise como um método de tratamento, um método de investigação, além de uma nova disciplina científica, no quadro dessa tripla partição, o caso clínico ocupa um lugar privilegiado, pois envolve, articula e unifica essas três qualificações.

Um caso clínico emerge de uma experiência singular de tratamento e constitui uma versão particular do método de investigação, que se forma em um (re)arranjo dos elementos do discurso do sujeito que se depositam a partir de nossa inclinação para escutá-los, e pode aspirar a exprimir achados e evidências (Figueiredo, 2004; Dunker, Ramirez \& Assadi, 2017).

Vorcaro (2018) e Queiroz (2002) destacam algumas das funções do caso clínico e de sua escrita, quais sejam:

a) A função de exponenciar o saber adquirido com os ensinamentos do caso, tornando-o capaz de interrogar, reformular, distinguir ou ultrapassar o que já foi apresentado pela teoria psicanalítica;

b) A função de literalidade do escrito: só na literalidade da narrativa do caso clínico poderemos reconhecer e distinguir o que há de singular na clínica. Tal literalidade é cara à psicanálise, pois o que o analista grafa e apaga da clínica é o que concebe como relevante ou não, evidenciando que seu ato de escrever está regulado pela responsabilização quanto ao seu ato clínico. Dizer da regulação do escrito pela clínica é ressaltar que o escrito submete-se, às mesmas regras estruturais do ato clínico, queira ou não, saiba ou não. Dessa forma, a transmissão da clínica psicanalítica pelo que dela se escreve constringe o que há de singular no encontro-desencontrado dessa experiência. O real, ou o singular da clínica, que o clínico necessariamente desconhece, só pode ser abordado depois de ter sido transposto para outro sistema de registro: a escrita;

c) A função de problematizar a generalização necessária à teoria. A escrita de um caso clínico na pesquisa em psicanálise não tem a intenção de ser meramente demonstrativa, muito menos de servir apenas para exemplificar conceitos;

d) A função de servir de matéria-prima essencial à ancoragem de conceitos e/ou metáforas, ser a base para construções metapiscológicas de modo a elaborar um novo saber no corpo da psicanálise.

No entanto, até a publicação de um caso, uma longa trajetória terá sido percorrida pelo analista, que se propõe a escrevê-lo. O caso clínico insere-se em uma série composta por momentos conexos: tratamento, supervisão, construção de caso e escrita. A escrita que visa publicação é realizada a partir da produção de uma pesquisa retrospectiva, na qual há a transposição da finalidade clínica para a finalidade científica (Dunker \& Zanetti, 2017).

A título de ilustração, apresentamos a experiência de construção escrita de casos para publicação, desenvolvida a partir de articulações entre universidade, instituições de formação e rede de atendimento de São Paulo, a Rede Clínica do Instituto de Psicologia da USP/SP, coordenada por Clarice Paulon, Natalie Mas e Priscilla Santos entre 2006 e 2016. Como fruto dessa experiência Dunker e Zannetti (2017) apresentam um procedimento experimental para a produção de casos clínicos:

a) Parte-se de um tratamento psicanalítico, que poderá ter se desenrolado tanto em um contexto institucional (hospital, ambulatório, clínicas-escola) quanto em um consultório privado. Tal tratamento se faz acompanhar de supervisão por parte de um psicanalista, em geral mais experiente. Por livre decisão do psicanalista e do supervisor, o caso poderá ser eleito para ser exposto em uma reunião de discussão coletiva;

b) Redige-se um texto, sob o qual se faculta liberdade estilística e se estimula a variedade de formas expositivas;

c) Realiza-se a apresentação de um escrito, que será lido para um grupo de pesquisadores e um psicanalista. Da leitura devem emergir observações espontâneas (problemática ou as questões veiculadas pelo caso, 
considerações acerca de interpolações, equívocos e efeitos gerados pela experiência de leitura e o tipo de transformatividade gerada pelo caso);

d) Os efeitos de leitura são reintegrados ao material escrito conforme a deliberação do clínico, que apresenta novamente o material em uma outra sessão de leitura e escuta. $\mathrm{O}$ fato de que casos tenham sido reescritos, por vezes ao longo de dez anos, confere ao resultado uma força longitudinal raramente encontrada na casuística psicanalítica;

e) Os casos, assim construídos, criam relações de oposição, continuidade, homologia ou analogia com outros casos construídos. Segundo esta regra de formação, permite-se verificar a repetição de certas estratégias e soluções obtidas no trabalho de redação e reescrita.

A partir da experiência descrita, podemos identificar dois processos que se alternam na construção escrita desses casos: a passagem do oral, do tratamento, para a escrita (do caso), depois a passagem da leitura do caso para a oralidade das considerações e, em seguida, novamente a passagem para o escrito, considerando os efeitos de compreensão, apagamento e esquecimento. Se o primeiro processo lida com as alternações da temporalidade do escrito com a temporalidade da fala, o segundo maneja a alternância entre a escrita de um e a escuta de vários, fazendo emergir a dimensão do coletivo, na passagem do material privado do caso para a sua dimensão publicável (Dunker, Ramirez \& Assadi, 2017).

É válido ressaltar que no Brasil contamos com uma produção de pesquisa em psicanálise já densa e consubstancial em contextos de pós-graduação, permitindo que a universidade cumpra seu papel na garantia da produção de conhecimento alinhada às demandas da sociedade e que a psicanálise siga implicada com o fazer pesquisa em contextos para além dos tradicionais.

Como podemos observar no exemplo citado, a proposição de casos clínicos em psicanálise nos contextos de pesquisas universitárias pode ser composta por procedimentos e estratégias que visam operar a travessia do fazer clínico propriamente dito para a tessitura da escrita, revelando-se um trabalho de elaboração importante no trilhamento de se autorizar pesquisador.

Para além desse aspecto, podemos pensar que o tempo, o lugar e a função de uma construção escrita, acerca de um encontro analítico, pode nos arremessar à dimensão do infamiliar e da incompletude, tal como na frase de Clarice Lispector citada na abertura desta seção: “Às vezes escrever uma só linha basta”.

\section{Tessitura da escrita de caso: efeitos para o analista e transmissão da psicanálise}

Sim, mas não esquecer que para escrever não importa o quê, o meu material básico é a palavra. Assim, é que esta história será feita de palavras que se agrupam em frases e destas se evola um sentido secreto que ultrapassa palavras e frases.

Lispector, 1998, p. 14-15.

Com base na apresentação e na publicação de casos como "Dora" e o "Homem dos Ratos", percebemos que Freud também se ocupava de um trabalho posterior ao encerramento dos casos, de registro e elaboração visando a comunicação e/ou a publicação de seus casos encerrados, deixando claro que a reconstrução da experiência pela escrita teórica tem o objetivo de produzir evidências, que podem se apresentar como provas em favor de suas teses, e isso em três domínios: clínico, lógico e terapêutico (Zanetti \& Kupfer, 2006).

Freud, ao longo de sua trajetória, reconfigurou em muitos aspectos a sua escrita de casos clínicos. Tais modificações ocorrem conforme o desenvolvimento dos conceitos psicanalíticos, articulando teoria, método clínico e prática psicoterápica. 
Essas articulações aconteceram devido a alguns conceitos-chave apresentados que reestruturaram critérios narrativos (Paulon, 2017). Mas como compor a escrita de um caso clínico?

$\mathrm{Na}$ esteira de reflexões acerca da formalização de casos clínicos, podemos pontuar que os casos clínicos de Freud, principalmente os mais longos, apresentavam determinadas estratégias de composição literária e formas de apresentação do material, tais como a exposição em duas partes, uma mais descritiva e outra mais interpretativa, o trabalho com fragmentos e indícios, o detalhamento dos primeiros movimentos do caso, o suspense e a revelação de elementos de maneira gradual (Zanetti \& Dunker, 2017; Fender \& Moretto, 2020).

Entre as possibilidades de transmissão no nível da escrita, podemos destacar a formalização e a matemização. A formalização seria uma tentativa de revelar por meio da escrita as sequências lógicas e as operações inconscientes latentes e determinantes dos fenômenos clínicos que ultrapassam os dados percebidos. A matemização deve-se a um esforço de abstração de Lacan, quando os símbolos funcionam como simplificadores da prática clínica (Chechia, 2004). Nesse contexto, questionase: para além das formas de composição do caso, quais elementos estão envolvidos no processo de escrita do caso?

Uma das principais considerações a essa indagação é que a escrita de casos não ocorre sem que o pesquisador psicanalista situe a si próprio também, visto que a análise se dá no espaço da transferência. O caso clínico é o efeito de uma relação transferencial e comporta os restos não assimiláveis de uma escuta. Dessa forma, a escrita pode se configurar como uma tentativa de elaborar o que restou como uma questão, o que reclama por uma simbolização, atravessando o processo de autorização do analista de se investir de um saber emprestado pelo paciente para poder dizer do caso enquanto acontecimento clínico e experiência teórica (Oliveira, 2004; Paulon, 2017).

Segundo Vorcaro (2018), transformar o atendimento clínico em um lugar de interrogação sobre a própria teoria psicanalítica e sobre sua transmissão convoca o analista a suportar o não sabido, testemunhando as ocorrências da clínica, problematizando conceitos que lhe são correlativos e expondo-se à refutação. Para tanto, é necessário que as ocorrências da clínica sejam acolhidas pelo analista, de modo a constituir um obstáculo à decisão interpretativa imediata. Ao produzir esse esgarçamento na continidade imaginária da teoria, problematizando o próprio desconhecimento, seus equívocos e seus encobrimentos, o analista se detém na estranheza que a clínica oferece à compreensão. A escrita do caso mostra que o analista está submetido à clínica, e é falado pelo seu escrito muito mais do que saberia dizer.

Segundo Dunker e Zanetti (2017), outra consideração relevante que envolve a construção escrita do caso com finalidade científica é a exigência do deslocamento do analista praticante do "lugar de agente" do discurso, que é o lugar que deve ocupar no tratamento, para o "lugar de trabalho". Tal deslocamento discursivo é necessário, pois o lugar de agente do discurso, "ocupado pelo objeto $a$ - ...em posição de causa de desejo - não se compatibiliza com a posição de pesquisador" (p. $35)$.

Para elucidar essa afirmação, Dunker e Zanetti (2017) propõem a partir leitura do matema do 'discurso do analista' desenvolvido por Lacan (1969-1970/1992), que os lugares preestabelecidos pela estrutura do discurso na pesquisa, no tratamento, na supervisão e na construção retrospectiva do caso clínico, devem se dar necessariamente no lugar do trabalho. No tratamento quem ocupa esse lugar é o analisante; na supervisão é o analista supervisionado; e na pesquisa retrospectiva o analista está na posição de pesquisador, conforme ilustra o quadro a seguir.

No discurso do analista, o 'lugar do agente' (acima à esquerda) é ocupado pelo objeto causa do desejo, o 'lugar do trabalho' (acima à direita) é ocupado pelo sujeito dividido (\$), já no 'lugar da produção e da perda' (abaixo a direita) está o $\left(S_{1}\right)$ significante mestre das identificações e do Ideal, e o saber $\left(S_{2}\right)$, está no 'lugar da verdade' (p. 35). 


\section{Os quatro lugares}

Agente
Verdade $\quad \begin{aligned} & \text { Outro/Trabalho } \\ & \text { Produção/Perda }\end{aligned}$

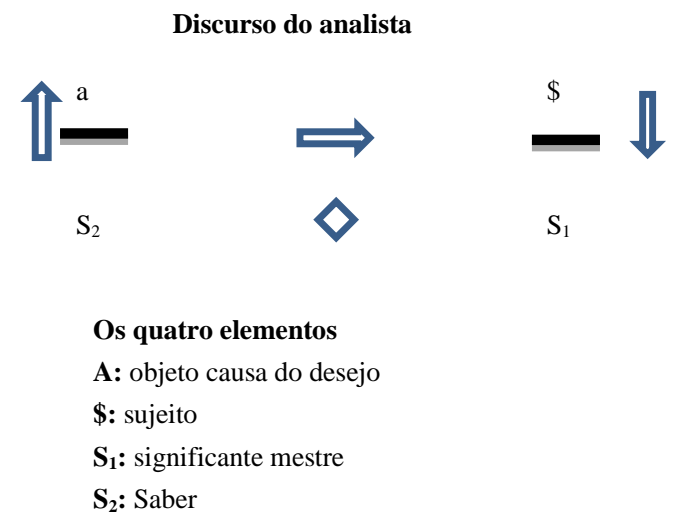

Fonte: Dunker e Zanetti (2017, p. 35).

Portanto, segundo a proposição dos autores, esse deslocamento exigido do analista na supervisão e na escrita para a posição de trabalho implica a possibilidade da reapropriação do saber pelo analista na condição de pesquisador.

Após essas considerações acerca dos elementos envolvidos na escrita de um caso, podemos discutir os efeitos desse processo para o analista/pesquisador. Uma das funções mais importantes da escrita de um caso para o psicanalista que o colige, é a possibilidade de terminar a transferência pelo lado do analista, de separar-se do analisante, de fazer o luto do processo vivido, como parte de uma elaboração necessária à dissolução da lógica transferencial que comandou o caso, possibilitando que ele ocupe a função de autor e se desligue da função do psicanalista (Dunker \& Zanetti, 2017).

Estamos acostumados a pensar a transferência somente do lado do analisando, mas acompanhando o percurso freudiano, reconhecemos no analista os efeitos de ser tomado nas transferências em seu trabalho cotidiano. Ou seja, toda saída da transferência deixa restos que não são completamente transpostos durante o trabalho analítico. Esses restos são derivados para as produções em psicanálise. Nesse sentido, parece que eles se colocam do lado das produções que ensinam (Costa, 2016).

Considerando as funções da escrita do caso aqui expostas, é válido destacar que escrever a clínica é um ato simbólico que não só permite a metaforização da experiência psicanalítica, mas também possui efeitos, entre eles, a transmissão.

Porge (2000) destaca as diferentes modalidades de transmissão $d a$ e $n a$ psicanálise, destacando que entre o $n a$ e o da, poderíamos pensar em situar seus modos como intensão e extensão. O grande problema a ressaltar, no entanto, é o modo de articulá-los. Afinal, a transmissão na psicanálise diz respeito aos efeitos de transmissão que se produzem entre analisante e analista, que concernem à relação com o inconsciente. Quando transmitimos um saber a outros a fim de informá-los, estamos no campo da transmissão da psicanálise, ou seja, no campo da extensão. Quando transmitimos um savoir-faire [saber-fazer], estamos transmitindo um método que permitirá a outros o contato com a experiência no campo de intensão. Pommier (1992), por sua vez, destaca que a psicanálise possui um corpo de enunciados que é transmissível, mas que não permite que se compreenda a singularidade da experiência analítica. Dessa forma, a transmissão deve ser entendida como o que articula o saber ao não saber concernente à experiência, não podendo ser reduzida a mero ensino, haja vista que ele remete o analista ora à análise pessoal, ora ao ensino teórico (Jorge, 2006).

Segundo Lacan (1978), a psicanálise tem sempre algo de intransmissível, e cada analista é forçado a reinventar a 
psicanálise. Sendo não-toda, podemos destacar que o modelo para a transmissão deve ser pensado próximo à experiência do inconsciente. Assim, a transmissão é também o encontro com um ponto intransmissível (Porge, 2009).

No entanto, a comunicação de um caso com a finalidade de transmissão acarreta dificuldades, um problema que Freud já enfrentava quando expôs sua preocupação em relação ao modo como os médicos leriam seus casos. Ou seja, mesmo elaborando um caso, conectando os operadores teóricos e clínicos construídos a partir dos fragmentos e elementos que dele se decantaram, é preciso considerar como essa construção será comunicada e a quem ela está endereçada (Fender \& Moretto, 2020).

Não importa muito que saibamos o resultado ou a solução do caso enquanto um enigma, mas a maneira como ele é comunicado. Assim, a transmissão está mais relacionada ao como (comunicação) do que ao porquê (enquanto solução). Ela depende do interlocutor. Estamos falando da necessidade de produzir diferentes maneiras de realizar uma comunicação. Embora estejamos tratando de um mesmo saber transmissível, é preciso circunscrever algo do real, a verdade extraída da construção de um caso. Há, assim, uma fenda entre a transmissão e a comunicação. A transmissão não vem necessariamente com a comunicação, mas depende dela (Fender \& Moretto, 2020).

Considerando o exposto por esses autores, destacamos que a tessitura escrita de um caso clínico em psicanálise visando a publicação em contextos como o universitário deve considerar seus interlocutores/leitores/debatedores. Além disso, precisam ser considerados alguns aspectos advindos dos mecanismos instituídos e regulatórios da ética em pesquisa no referido contexto, tais como: (a) preservar a identidade do paciente; (b) utilizar casos clínicos encerrados; (c) submeter o projeto de pesquisa ou projeto de relato de caso a um comitê de ética em pesquisa; (d) realizar um aprofundamento dos operadores teórico-clínicos; (e) trabalhar com fatos clínicos e não com dados clínicos em profundidade e extensão (Dallazen et al., 2012).

Diante do exposto, destacamos que, além de ser uma mera descrição como nas ciências positivas, a tessitura da escrita de um caso em psicanálise em contexto de pesquisa possui funções para o analista/pesquisador, que precisa realizar a travessia do clínico para autor.

Além do mais, há implicações éticas e políticas, que emergiram neste trabalho na figura da transmissão, que, apesar de atravessada pelos rigores dos operadores teórico-clínicos, parte do enigma que extraímos da citação de Clarice Lispector, apresentada no início desta seção, ou seja, da impossibilidade de tudo dizer/escrever, que destaca também uma transmissão que se dá no registro do real.

\section{Considerações Finais}

Neste ensaio as articulações teóricas tiveram o objetivo de circundar a questão da importância da escrita de casos clínicos em contextos de pós-graduação. Por meio da incursão na literatura especializada, tecemos a presente pesquisa teórica em psicanálise, construindo alguns pontos para análise e reflexão:

a) A psicanálise é um método que congrega uma multiplicidade de estratégias. Contudo, não se pode negar que a fonte primeira e original de seu método o caso clínico, que advém da experiência direta com paciente ao longo do tratamento, portanto um lugar privilegiado no que tange à produção de pesquisas.

b) $\mathrm{O}$ analista que se propõe a escrever sobre um caso se vê capturado por um enigma, que o faz desejar tecer a escrita, que tem como função não só interrogar a teoria, mas também buscar o que nos remete ao real do caso, aquilo que toca o não dito, o singular da clínica ancorado em construções metapsicológicas.

c) Na tessitura da escrita de um caso, podemos extrair efeitos para o analista e para a transmissão da psicanálise, já avisados de que a escolha das palavras e a forma como o analista/pesquisador escreve e transmite desvelam aspectos transferenciais.

d) O trabalho de escrita do caso permite ao analista separar-se do analisante, por meio de um trabalho de luto, como 
parte de uma elaboração necessária para a dissolução da lógica transferencial. Na trilha desse trabalho, que é estrutural, outro deslocamento é exigido do analista para a posição de trabalho, que implica a possibilidade da reapropriação do saber na condição de pesquisador.

e) No que diz respeito à transmissão, destacamos que a psicanálise possui um corpo de enunciados passível de transmissão, mas que não dá garantias de imersão na lógica singular da experiência analítica, desvelando sua dialética a partir da proposição de sua intransmissibilidade.

À guisa de concluir, é valido destacar que, na experiência de escrever este trabalho, vários diálogos puderam ser travados, tanto entre os autores quanto os internos por parte de cada pesquisador. Desses diálogos emergiram aspectos inerentes à subjetividade dos proponentes do ensaio, tais como a responsabilidade de escrever sobre a escrita, a vivência caótica de organizar o texto e até o prazer de arriscar escrever algumas linhas, que, como pudemos aprender com Clarice Lispector, "basta apenas uma". E como marca singular do encontro com este texto, e frente aos desafios de tecê-lo, podemos considerar a dimensão não-toda da escrita, mas acima de tudo apostar que não devemos recuar frente ao desafio de escrever a clínica.

Destacamos que a partir da escrita do presente trabalho, do trilhamento em busca de tecer articulações teóricas para "responder" de forma não-toda o problema de pesquisa deste artigo, outras questões se desvelaram de forma consubstancial. Dentre os temas a possibilidade de construção coletiva de uma metodologia para escrita do caso, a questão da transferência com o texto escrito e seus desdobramentos, o lugar do pesquisador psicanalista em instituições Universitárias e os aspectos éticos em torno da construção do caso clínico psicanalítico. Tais temas e outros que possam advir da leitura e transferência do leitor com o escrito podem se constituir enquanto terreno fértil para a elaboração de novos estudos e pesquisas em psicanálise.

\section{Referências}

Associação Brasileira de Educação a Distância. (S/D) Guia para submeter trabalhos para os congressos e publicações da ABED. A distinção entre o ensaio e o relatório de pesquisa. http://www.abed.org.br/documentos/Guia_Submissao_de_TCs_ABED.pdf.

Associação a clínica freudiada (S/D). Seminário 10: a angústia. http://www.clinicafreudiana.com.br/freudiana2.qps/Ref/SYSK-AVT5TS

Almeida, S. F. C. (2006). Transmissão da psicanálise a educadores: do ideal pedagógico ao real da (trans)missão educativa. Estilos da Clinica, 11(21), 14-23.

Borch-Jacobsen, M. e Shamdanasi, S. (2012). Os arquivos de Freud. Unesp.

Castello, J. (2011). Clarice na cabeceira. Rocco.

Checchia, M. A. (2004). Considerações iniciais sobre lógica e teoria lacaniana. Psicologia USP, 15(1-2), 321-338. DOI: https://doi.org/10.1590/S010365642004000100028 .

Costa, A. \& Leite, N. (2016). A escrita do caso. Revista Lacuna, 2(1), s/p.

Crews, F. (1999). As guerras da memória: o legado de Freud em xeque. Paz e Terra.

Dallazen, L, Giacobone, RV., Macedo, M. M. K. \& Kupermann, D. (2012). Sobre a ética em pesquisa na psicanálise. Psico, 43(1), 47-54.

Dunker, C. I. L, Ramirez, H \& Assadi, T. (2017). A construção de casos em psicanálise: método clínico e formalização discursiva. Annablume.

Dunker, C. I. L. (2018). A garrafa de Klein como método para formalização de casos clínicos em psicanálise. In C.I.L. Dunker, \& C. E. Zanetti (Eds.), A construção de casos em psicanálise: método clínico e formalização discursiva. (pp. 181-231). São Paulo: Annablume.

Dunker, C. I. L \& Zanetti, C. E. (2017). Construção e formalização de casos clínicos. In C. I. L. Dunker, \& C. E. Zanetti (Eds.), A construção de casos em psicanálise: método clínico e formalização discursiva. (pp. 23-45). São Paulo: Annablume.

Fender, W.D \& Moretto, M.L.T. (2021). Construir, comunicar, transmitir: um caminho possível para o analista em uma equipe multidisciplinar. Rev. SBPH, 23(1), 3-15.

Fernandes, A. H. (2017). O ensino e a transmissão da psicanálise. Stylus, 34(1), 93-102.

Ferreira, T. \& Vorcaro, A. (Eds.) (2018). A transmissão e saber em psicanálise: (in)passes da clínica. In T. Ferreira, \& A. Vorcaro. Pesquisa e psicanálise: do campo à escrita. (1a ed.). Belo Horizonte, MG: Autêntica. 
Research, Society and Development, v. 10, n. 11, e296101119639, 2021

(CC BY 4.0) | ISSN 2525-3409 | DOI: http://dx.doi.org/10.33448/rsd-v10i11.19639

Figueiredo, A. C. (2004). A construção do caso clínico: uma contribuição da psicanálise à psicopatologia e à saúde mental. Revista Latinoamericana de Psicopatologia Fundamental, São Paulo, SP, vol. 7(1), 75-86.

Jorge, M. A. C. (2006). Lacan e a formação do psicanalista. Contra Capa.

Lacan, J. (1992). O seminário, livro 2: O eu na teoria de Freud e na técnica da psicanálise. Zahar.

Lacan, J. (2008). O seminário, livro 16: De um Outro ao outro. Zahar.

Leitão, I. B. (2018). A construção do caso clínico em psicanálise: revisão da literatura. Contextos Clínicos, 11(3), 410-424. DOI: http://dx.doi.org/10.4013/ctc.2018.113.11.

Lispector, C. (1998). A hora da estrela. Rio de Janeiro. Rocco.

Loureiro I. (2002). Sobre algumas disposições metodológicas de inspiração freudiana. In Q. E. Freire, \& S. A. R. Rodrigues (Eds.) Pesquisa em psicopatologia fundamental. (pp. 143-156). São Paulo: Escuta.

Monteiro, M. P (2014). A topologia de Lacan. Estudos de Psicanálise, 41(1), 133-139.

Nasio, J-D. (2001). Os grandes casos de psicose. Zahar.

Nogueira, LC. (1998). A psicanálise: uma experiência original - o tempo de Lacan e a nova ciência. Tese (Livre-docência em psicologia clínica) - Instituto de Psicologia, Universidade de São Paulo, SP, Brasil.

Oliveira, I. M. A. (2004). O caso clínico na instituição pública: polifonias desejantes. Revista Latinoamericana de Psicopatologia Fundamental, 7(3), 8293. DOI: https://dx.doi.org/10.1590/1415-47142004003008.

Paulon, P. C. (2017). Introduzindo o conceito de narrativa em psicanálise: sobre um operador comparativo para o estudo de casos clínicos. Tese de Doutorado em Psicologia Clínica, Programa de Pós-graduação em Psicologia clínica, Instituto de Psicologia, Universidade de São Paulo, Brasil.

Pommier, G. (1992). A neurose infantil da psicanálise. Zahar.

Porge, E. (2000). Sobre a transmissão da psicanálise. Revista do Encontro sobre a Transmissão da Psicanálise, 26-27.

Porge, E. (2009). Transmitir a clínica psicanalítica: Freud, Lacan, hoje. Unicamp.

Queiroz, E. F. (2005). Inclinar-se para a escuta e inclinar-se para a escrita. Pulsional Revista de Psicanálise, São Paulo, 18(184), 60-64.

Quinet, A. (2009). A estranheza da psicanálise: a escola de Lacan e seus analistas. Zahar.

Roazen, P. (1999). Como Freud trabalhava. Companhia das Letras.

Rosa, M. D. (2001). Psicanálise na universidade: considerações sobre o ensino de psicanálise nos cursos de psicologia. Psicologia USP, 12(2), 189-199. DOI: https://doi.org/10.1590/S0103-65642001000200016.

Sousa, E. L. A. (2000). (A vida entre parênteses) - o caso clínico como ficção. Psicologia clínica, 12(1), 11-19.

Tavares, L. A. T \& Hashimoto, F. (2013). A pesquisa teórica em psicanálise: das suas condições e possibilidades. Gerais: Revista Interinstitucional de Psicologia, 6(2), 166-178.

Zanetti, S. A. S e Kupfer, M. C. M. (2006). O relato de casos clínicos em psicanálise: um estudo comparativo. Estilos da Clínica, 9(21), 170-185. 